\title{
EDUCAÇÃO AMBIENTAL NO \\ SEMIÁRIDO BAIANO: CONHECIMENTO, \\ APLICAÇÕES E NECESSIDADES
}

\author{
Regina Nascimento ${ }^{1}$ \\ Eliane Maria de Souza Nogueira² \\ Paulo Roberto Ramos ${ }^{3}$
}

Resumo: A Educação Ambiental(EA) é um instrumento de potencialização da causa ambiental tutelada pela Legislação Pátria. Nesse cenário, o estado da Bahia instituiu a sua Política Estadual de Educação Ambiental (PEEA/BA), através da Lei 12.057 de 07 de janeiro de 2011, que traz a EA como uma série de estratégias visando à sustentabilidade socioambiental. Com o objetivo de verificar o conhecimento, as aplicações e necessidades da Educação Ambiental pelos docentes à luz da PEEA/BA, foi realizada uma pesquisa de campo em uma escola do Semiárido baiano, com abordagem metodológica qualiquantitativa, circundada pelas pesquisas bibliográfica e documental. As reflexões sobre a realidade concreta e estudos semelhantes à temática apontam que há um descompasso entre as determinações da Lei com as políticas públicas e as práticas pedagógicas em EA.

Palavras-chave: Legislação Ambiental; Educação Formal; Bahia; Formação Continuada; Efetividade.

Abstract: Environmental Education $(E A)$ is an instrument of potentialization of the environmental cause, protected by the Homeland Legislation. In this scenario, the state of Bahia instituted its State Environmental Education Policy (PEEA / BA), through Law 12.057 of January 7, 2011, which brings EA as a series of strategies aiming at the environmental sustainability. In order to verify knowledge, applications and enviromental education's needs by teachers in light of PEEA / BA, a field research was carried out in a school in Bahia in the semiarid region, with a qualitative and methodological method, surrounded by bibliographical and documentary research.Reflections on concrete reality and similar studies thematics, indicates that, there is a mismatch between the determinations of the Law with public policies and pedagogical practices in EA.

Keywords: Environmental Legislation; Formal Education; Bahia; Knowledge; Effectiveness.

\footnotetext{
${ }^{1}$ Universidade do Estado da Bahia (UNEB). E-mail: regclaudia1@hotmail.com

2 Universidade do Estado da Bahia (UNEB). E-mail: emsnogueira@gmail.com

3 Universidade do Vale do São Francisco, Juazeiro (BA). E-mail: paulo.roram@gmail.com
} 


\section{Introdução}

A Educação Ambiental é um instrumento evidenciado na legislação e programas governamentais e institucionais do país e de alguns estados brasileiros, em decorrência das demandas da sociedade pós-década de 1970. Os seus postulados pregam uma educação acessível a todos os níveis e modalidades de ensino formal, de maneira interdisciplinar e transversal, visando a sustentabilidade socioambiental (BRASIL,1988,1999; CNE, 2012; BAHIA, 2011,2019).

A EA pode contribuir na tomada de decisões e atitudes para a resolução dos problemas em seus diversos aspectos, sejam naturais, sociais, políticos, econômicos e culturais, e isso pressupõe a formação de cidadãos atentos aos seus direitos e deveres (REIGOTA,2017). Nesse sentido, as leis são, em um primeiro momento, referências para a possibilidade da garantia de direitos e deveres dos cidadãos, tal qual o direito a Educação Ambiental, constituindo-se em uma obrigatoriedade dos estabelecimentos de ensino (BRASIL,1996).

Trazendo a EA para um contexto mais específico, o estado da Bahia elaborou e validou a Política de Educação Ambiental do Estado da BahiaPEEA/BA, através da Lei 12.056 de 07 de janeiro de 2011, regulamentada pelo Decreto 19.083 de 07 de junho de 2019, para ser implementada em todos os seus Terrítórios de Identidade (TI) (BAHIA,2011, 2019).

A PEEA/BA é uma política pública que apresenta em seu contexto formativo a influência dos preceitos do Tratado de Educação Ambiental para Sociedades Sustentáveis e Responsabilidade Global e a Carta da Terra, organiza planos de implementação em um determinado território, e deve ser institucionalizada como o cumprimento da obrigação do Estado em prover condições que facilitem a efetiva participação da sociedade em processos de tomada de decisão e gestão pública (RAYMUNDO; BRANCO; BIASOLI,2018; CERQUEIRA et al., 2019; GUERRA et al., 2019).

A PEEA/BA, ao tempo em que garante o direito dos estudantes à Educação Ambiental, impõe às unidades de ensino o dever de ofertá-la. No entanto, a existência de um referencial normativo deixa dúvidas se os docentes conhecem ou não a Lei que trata da Educação Ambiental da Bahia; se conhecem e cumprem os seus preceitos ou conhecem e encontram dificuldades ou não para a sua efetivação.

Diante desses questionamentos, foi realizada uma pesquisa de campo em uma escola do Semiárido baiano, de abordagem metodológica qualiquantitativa, circundada por pesquisas bibliográficas e documentais, com o objetivo de verificar o conhecimento, as aplicações e necessidades da Educação Ambiental pelos docentes à luz da PEEA/BA. Tal interesse reverberou-se em decorrência do vínculo da pesquisadora com a educação básica do estado da Bahia envolvendo a temática de $E A$, e a inquietação em conferir se os dispositivos da PEEA/BA são, de fato, conhecidos e aplicados na Educação Ambiental formal. 


\section{Metodologia}

\section{Caracterização da área de estudo}

O Semiárido Brasileiro (SAB) engloba oito estados da região Nordeste mais o Norte de Minas Gerais, nos quais estão distribuídos 1.263 municípios, em uma área de 1.128.697 $\mathrm{Km}^{2}$. Dentre os estados, o da Bahia tem 278 municípios que fazem parte do Semiárido, a exemplo do município de Curaçá (SUDENE,2017) (Figura 1). Apresenta clima semiárido, temperaturas predominantemente altas, regime pluvial irregular com longos períodos secos, chuvas ocasionais concentradas em poucos meses do ano, sendo a caatinga a vegetação predominante (ARAÚJO, 2011; FERREIRA, 2017).
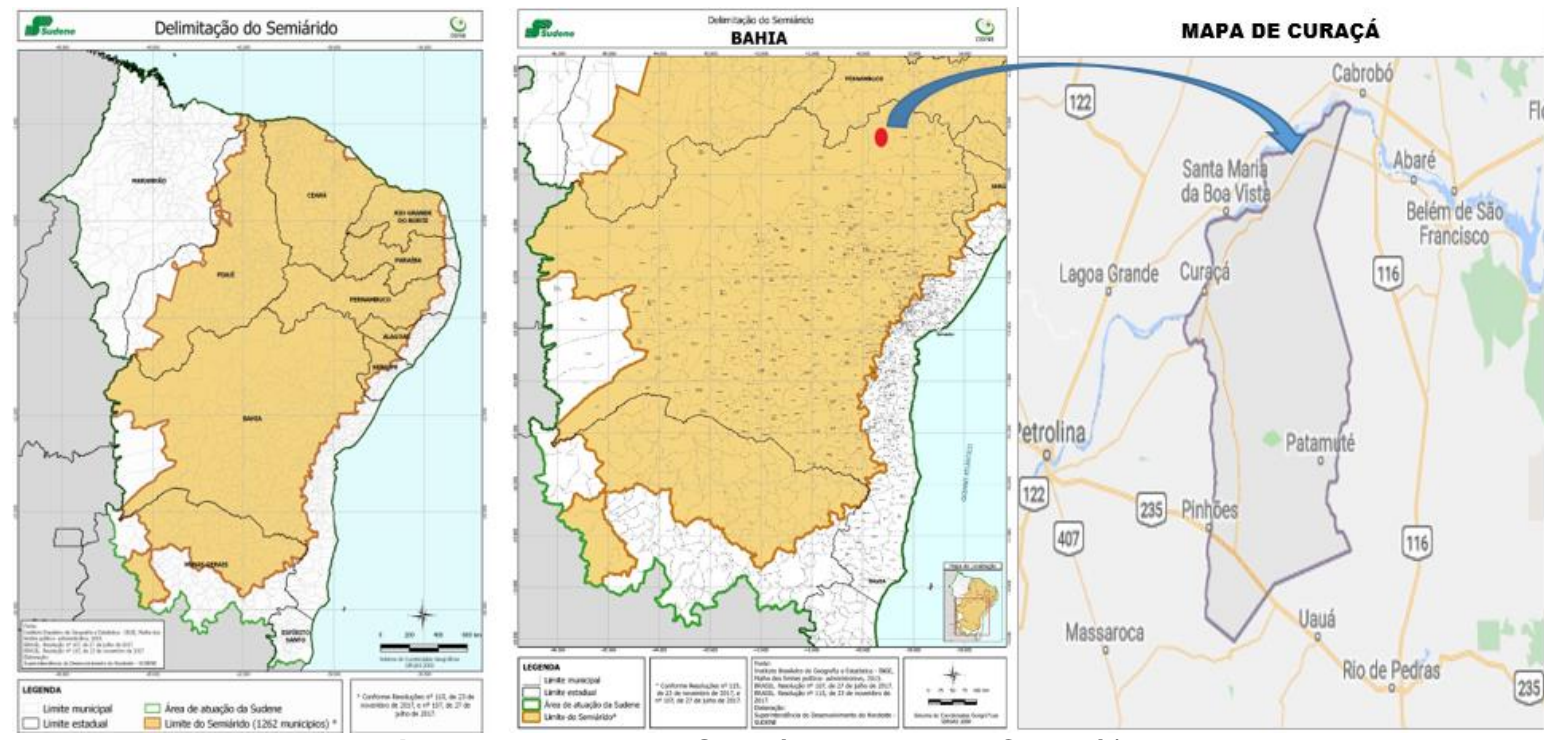

Figura 1: Mapas do Semiárido, Bahia e Curaçá/BA.

Fonte: SUDENE (2017), adaptado pelos autores.

A Bahia conta com 27 (vinte e sete) TI (Territórios de Identidade), que agrupam os 417 municípios baianos, cada um com características multidimensionais próprias, dentre os quais o $\mathrm{TI} 10$, que recebe o nome de Sertão do São Francisco, abrangendo a cidade de Curaçá-BA (SEPLAN/BA,2018). Os TI são definidos como o agrupamento identitário municipal, formado de acordo com critérios sociais, culturais, econômicos e geográficos e reconhecidos pela sua população como o espaço historicamente construído ao qual pertence, com identidade que amplia as possibilidades de coesão social e territorial (BAHIA,2010).

O município de Curaçá-BA situa-se no extremo norte da Bahia, a uma distância de $592 \mathrm{~km}$ da capital do Estado (Salvador), na microrregião do submédio São Francisco; possui uma área territorial de $6.442,19 \mathrm{Km}^{2}$ e uma população aproximada de 35.524 habitantes (SUDENE, 2017), residentes na zona rural e na zona urbana. Está territorialmente dividido entre 03 povoados e 05 distritos, dentre estes Riacho Seco, o maior de todos (PPP,2017). 
A pesquisa de campo foi realizada em uma Escola do Ensino Médio da Educação Básica do Estado da Bahia, situada no município de Curaçá, e teve seu nome resguardado por exigência do Comitê de Ética e Pesquisa (CEP), em atenção a Resolução 466/2012.

A Escola está sob a circunscrição do Núcleo Territorial de Educação NTE 10, Juazeiro-BA, e distancia-se, aproximadamente, $140 \mathrm{Km}$ desta cidade. O NTE 10 faz parte do território do Sertão do São Francisco, e abrange as escolas das cidades de Campo Alegre de Lourdes, Canudos, Juazeiro, Casa Nova, Uauá, Curaçá, Pilão Arcado, Remanso, Sento Sé e Sobradinho (IBGE; SEPLAN,2018)

De acordo com dados da Superintendência de Estudos Econômicos e Sociais da Bahia (SEI, 2019), através dos Indicadores Territoriais para o Território de Identidade do Sertão do São Francisco, gerados em 2019, o TI Sertão do São Francisco possui uma área de $61.610 \mathrm{Km}^{2}$, densidade geográfica de $8,8 \mathrm{hab} / \mathrm{km}^{2}$, população com mais de 530 mil habitantes, abrange 10 municípios, sendo Juazeiro e Casa Nova os de maiores destaques por apresentarem as maiores populações. No TI 10 há predominância da população na zona urbana $(63,9 \%)$.

Quanto à educação, o TI do Sertão do São Francisco apresentava uma taxa de analfabetismo de $20 \%$ contra $16 \%$ de analfabetismo em todo o estado da Bahia, no ano de 2010, e 51 estabelecimentos de ensino médio mantidos pelo poder público estadual no ano de 2016; as principais atividades econômicas de 2017 foram a agropecuária $(9,2 \%)$, indústria $(13,2 \%)$ e comércio e serviços $(69 \%)$, sendo os três setores de atividades que mais empregaram formalmente em 2017 , o da administração pública(18.106 vagas), comércio(12.115 vagas) e agropecuária, extração vegetal, caça e pesca(10.621 vagas) (SEI/BA,2019).

Quanto à estrutura física, o Colégio Estadual possui um porte pequeno, com apenas cinco salas de aulas, com capacidade entre 25 e 45 alunos cada. Conta com 15 profissionais da educação distribuídos em direção, vice direção, coordenador pedagógico, secretária, professores e articuladores de área e atende a uma clientela de aproximadamente 250 alunos, segundo dados do Projeto Político Pedagógico da Escola (PPP, 2017).

\section{Procedimentos metodológicos}

Este estudo utilizou pesquisas bibliográfica, documental e de campo. A pesquisa bibliográfica, atemporal, deu-se com ênfase na epistemologia da Ecologia Humana construída no decorrer do curso de mestrado em Ecologia Humana e Gestão Socioambiental da Universidade do Estado da BahiaUNEB(material impresso e digital), livros físicos e através de buscas online de periódicos nas bases de dados Scielo e Google Acadêmico, de publicações do tipo artigo e livros na língua portuguesa relacionados à Educação Ambiental, usando como palavras-chave: "Lei EA Bahia", "Educação Ambiental", 
"Educação Ambiental Semiárido baiano" , "Território de Identidade Sertão do São Francisco", "EA crítica e contextualizada", "Formação continuada em EA" e outras correlatas ao assunto.

A pesquisa documental ocorreu em fontes legais e institucionais como a Constituição Federal de 1988, leis, decretos, programas governamentais, resoluções e Projeto Político Pedagógico (PPP) da unidade de ensino pesquisada, com ênfase na Política de Educação Ambiental da Bahia (Lei 12.056/2011). De acordo com Dutra e Terrazan(2012), a pesquisa documental antecede e acompanha a pesquisa de campo, bem como visa a mostrar a situação atual de um determinado assunto.

A pesquisa de campo, na forma de estudo de caso, teve como primeiro passo para a sua realização, o contato com a responsável pela gestão da Escola, coordenadora e professores, para a apresentação da sua proposta, no mês de julho de 2018, e contou com a anuência dos profissionais de educação da escola.

Em seguida, o Projeto de Pesquisa foi encaminhado ao Comitê de Ética e Pesquisa-CEP, atendendo as recomendações da resolução 466/2012 e aprovado sob o parecer $\cong 3.186 .982$ e Certificado de Apresentação para Apreciação Ética - CAAE, no 07807219.9.0000.8089.

Antes da coleta de dados foi feita uma reunião com a comunidade escolar, em março de 2019, para o detalhamento do cronograma, reiteração da proposta da pesquisa e o convite, mais uma vez, para que a comunidade escolar participasse do estudo. Os participantes- dez docentes- assinaram o Termo de Consentimento Livre e Esclarecido-TCLE, ficando uma cópia com a pesquisadora e uma cópia com os inquiridos, devidamente adaptado aos princípios éticos exigidos pelos órgãos de produção de pesquisas, em que foi esclarecido previamente pela pesquisadora que o nome da escola e de todos os participantes ficariam no anonimato, atendendo a recomendação do Código de Ética e Pesquisa.

Quanto à abordagem metodológica, a pesquisa foi qualiquantitativa, uma abordagem mista, que inclui a pesquisa quantitativa e qualitativa. Qualitativa, uma vez que se utilizou da linguagem matemática, quantificada; qualitativa, por investigar a realidade e explicá-la a partir da percepção dos sujeitos (FERREIRA, 2011). Quanto ao objetivo, a pesquisa foi exploratória, uma vez que permitiu ao pesquisador maior contato com o tema pesquisado; descritiva, ao detalhar as características, fatores ou variáveis que se relacionam com a temática estudada; e explicativa, uma vez que permitiu aprofundar o conhecimento da realidade (DUARTE,2019).

A coleta de dados foi feita mediante questionários semiestruturados com perguntas abertas e fechadas aos docentes, com base nos objetivos a alcançar. As questões compuseram-se de identificação pessoal e profissional e sobre o conhecimento e percepção acerca da Educação Ambiental com base nos preceitos da legislação baiana. A investigação foi feita em horários 
variados, de acordo com as Atividades Complementares (AC's) dos professores. Contou-se, também, com a consulta ao Projeto Político Pedagógico da escola (PPP).

A análise dos dados quantitativos foi realizada através de estatística descritiva simples. A análise qualitativa obedeceu aos critérios de Bardin (2002), passando pela pré-análise, exploração do material e resumo dos resultados obtidos.

\section{Resultados e discussões}

\section{Perfil social e profissional dos docentes}

A população do estudo foi composta por dez professores efetivamente lotados em uma escola pública de Curaçá. Entre os participantes, verificou-se que a maior parte é jovem, com idade compreendida entre 20 e 60 anos, com predominância de idades entre 31 e 40 anos, e com pouco tempo de atuação na educação, compreendido de 1 a 10 anos. O percentual de homens é pequeno, correspondendo a 30\% (3/10), apresentando tempo de docência $\leq a$ 10 anos (Tabela 1).

Todos os docentes pesquisados são graduados, com formação em Matemática, Letras, Ciências Biológicas e História. Outro aspecto observado, foi o fato de que alguns docentes não estão lotados em suas áreas de formação, como por exemplo, o professor de Ciências Biológicas ministra aulas de Geografia, Educação Física e Filosofia, e o professor de Letras ministra aulas de Geografia (Tabela 1). Como é uma escola de pequeno porte e metade dos docentes possui uma carga horária de 40 horas semanais, os docentes se veem obrigados a lecionar componentes curriculares diferentes das suas formações, para complemento de carga horária.

Os dados revelam que $40 \%(n=4)$ dos docentes não tiveram a temática de EA inserida em suas graduações. Dos $60 \%$ que foram contemplados com 0 referido tema, $40 \%$ tiveram apenas a teoria (Tabela 1), não obstante a Legislação em EA a recomendar em todos os níveis e modalidades de ensino, inclusive no ensino superior, desde a década de 1980 (BRASIL,1981,1988,1999; BAHIA 2011).

Pelos percentuais obtidos, provavelmente os docentes concluíram suas licenciaturas após a década de 1980, quando a EA começou a ser potencializada no Brasil e institucionalizada na educação formal com a Política Nacional de Educação Ambiental-Lei 9795/1999. 
Tabela 1: Perfil social e profissional dos docentes.

\begin{tabular}{|c|c|c|c|c|c|c|}
\hline Graduação & Gênero & Idade & $\begin{array}{c}\text { Tempo } \\
\text { de } \\
\text { docência }\end{array}$ & $\begin{array}{l}\text { Componente } \\
\text { curricular }\end{array}$ & $\begin{array}{c}\text { Carga } \\
\text { horária }\end{array}$ & $\begin{array}{c}\text { EA na } \\
\text { formação } \\
\text { académica }\end{array}$ \\
\hline Matemática & Masculino & $\begin{array}{c}20 a \\
30\end{array}$ & 1 a 5 & Matemática & 40 & $\begin{array}{c}\text { Sim, } \\
\text { apenas } \\
\text { teoria }\end{array}$ \\
\hline Matemática & Feminino & $\begin{array}{c}31 \mathrm{a} \\
40\end{array}$ & 21 a 25 & Matemática & 40 & Não \\
\hline Letras & Feminino & $\begin{array}{c}31 \mathrm{a} \\
40 \\
\end{array}$ & 6 a 10 & Português & 40 & Não \\
\hline $\begin{array}{l}\text { Ciências } \\
\text { Biológicas }\end{array}$ & Feminino & $\begin{array}{c}31 \mathrm{a} \\
40\end{array}$ & 6 a 10 & Biologia & 20 & $\begin{array}{l}\text { Sim, teoria } \\
\text { e prática }\end{array}$ \\
\hline História & Feminino & $\begin{array}{c}51 \mathrm{a} \\
60\end{array}$ & 21 a 25 & $\begin{array}{l}\text { História e } \\
\text { Sociologia }\end{array}$ & 40 & $\begin{array}{c}\text { Sim, } \\
\text { apenas } \\
\text { teoria }\end{array}$ \\
\hline Letras & Feminino & $\begin{array}{c}31 \mathrm{a} \\
40\end{array}$ & 6 a 10 & $\begin{array}{c}\text { Português, } \\
\text { Inglês, Arte, } \\
\text { Filosofia e } \\
\text { Redação }\end{array}$ & 40 & Não \\
\hline Letras & Masculino & $\begin{array}{c}20 a \\
30\end{array}$ & 1 a 5 & Geografia & 20 & Não \\
\hline Matemática & Feminino & $\begin{array}{c}31 \mathrm{a} \\
40\end{array}$ & 1 a 5 & Física & 20 & $\begin{array}{c}\text { Sim, } \\
\text { apenas } \\
\text { teoria }\end{array}$ \\
\hline $\begin{array}{l}\text { Ciências } \\
\text { Biológicas }\end{array}$ & Masculino & $\begin{array}{c}20 a \\
30\end{array}$ & 6 a 10 & $\begin{array}{l}\text { Biologia, } \\
\text { química e } \\
\text { Filosofia }\end{array}$ & 20 & $\begin{array}{l}\text { Sim, teoria } \\
\text { e prática }\end{array}$ \\
\hline $\begin{array}{l}\text { Ciências } \\
\text { Biológicas }\end{array}$ & Feminino & $\begin{array}{c}31 \mathrm{a} \\
40\end{array}$ & 1 a 5 & $\begin{array}{c}\text { Geografia, } \\
\text { Educação } \\
\text { Física e } \\
\text { Filosofia }\end{array}$ & 20 & $\begin{array}{c}\text { Sim, } \\
\text { apenas } \\
\text { teoria }\end{array}$ \\
\hline
\end{tabular}

Fonte: Elaborada pelos autores, a partir de dados da pesquisa.

Conforme evidenciou-se na pesquisa de campo em tela (Tabela 1), houve uma lacuna na oferta de EA em alguns cursos acadêmicos, assim como constatado nos trabalhos de Hofstatter; Oliveira; Souto (2016), em que se aferiu a existência de uma deficiência elevada na oferta de conteúdos socioambientais nos cursos de Licenciatura, inclusive, nos cursos de Pedagogia e outros cursos superiores, trazendo prejuízo para a sociedade e barreira para o alcance da sustentabilidade, o que demanda a formação socioambiental dos professores em exercício, na perspectiva crítica e contextualizada, principalmente estando em um bioma historicamente desvalorizado como a caatinga e a visão preconceituosa do semiárido e de sua população. 


\section{Perspectivas crítica e contextualizada da Educação Ambiental}

As perspectivas crítica e contextualizada da EA são princípios apresentados pela PEEA/BA ao recomendar a reflexão crítica sobre a relação entre indivíduos, sociedade e ambiente; e a contextualização do meio ambiente, considerando as especificidades locais, regionais, territoriais, nacionais e globais, e a interdependência entre 0 meio natural, 0 socioeconômico e o cultural, sob o enfoque da sustentabilidade (BAHIA, 2011, art. $\left.3^{\circ}\right)$.

Para Freire (2008), a educação crítica proporciona a formação de sujeitos sociais emancipados, ou seja, sujeitos autores da própria história. A EA, embora enfrente alguns desafios, pode ser uma prática emancipatória para a vida (TRISTÃO, 2016) e tem como objetivo principal o alcance da emancipação humana (SORRENTINO, 2013).

A formação continuada em EA na perspectiva crítica deve promover novos modos de ser e atuar no mundo, formando um "sujeito ecológico capaz de identificar e problematizar as questões socioambientais e agir sobre elas" (CARVALHO, 2008, p. 156-157). A EA crítica está inserida em um contexto mais amplo que o natural, como o contexto político, social, econômico e cultural (RODRIGUES; SANTOS; PEREIRA, 2016).

Quando questionados se os temas de Educação Ambiental são relacionados à vivência da comunidade escolar, ou seja, contextualizados, $60 \%$ dos docentes afirmam sim (Gráfico 1, próxima página), abordando temas sobre a reciclagem de resíduos sólidos, coleta seletiva do lixo e relação com o rio São Francisco, principal fonte de água da região, problemas vivenciados pelos ribeirinhos, segurança alimentar e visão agroecológica para produção do alimento, constituindo-se em um aspecto positivo da EA. Contudo, $40 \%$ dos docentes afirmaram não fazer relação dos seus componentes curriculares com as questões ambientais que os cercam. De igual modo, Barbosa e Santos (2015) verificaram em seus estudos que a EA contextualizada no Semiárido nordestino, principalmente no meio rural, ainda dista do ideal.

É tarefa da Educação Ambiental contextualizada ressignificar o território Semiárido, gerar novas práticas sociais, promover a cultura da convivência a partir do olhar das qualidades do semiárido brasileiro, antes significado pejorativamente em decorrência da visão hegemônica colonialista (CARVALHO,2012). Nesse sentido, é preciso um olhar descolonizado do Semiárido, na busca da sustentabilidade desse ecossistema de características próprias, mas não menos importantes que outros. 
Gráfico 1: Contextualização e referencial teórico nas práticas pedagógicas em EA, pelos docentes de uma escola pública de Curaçá-Bahia.

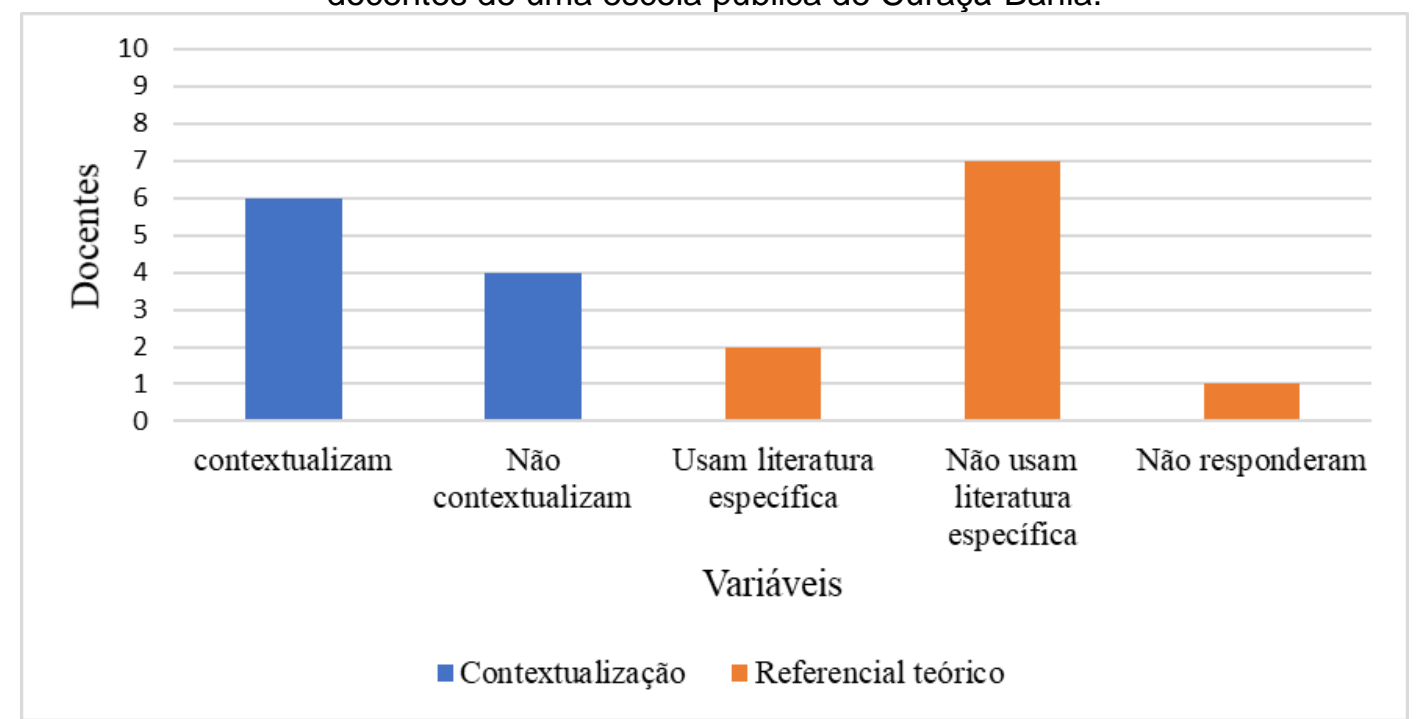

Fonte: Elaborado pelos autores, a partir de dados da pesquisa.

$\mathrm{Na}$ visão de Carneiro et al. (2016), as questões socioambientais do entorno da escola precisam fazer parte da educação formal, e esta levar em conta o conhecimento do mundo do estudante e sua relação com os problemas ambientais para a discussão e superação desses problemas a curto, médio ou longo prazos. O contexto serve como ponto de partida para a produção de conhecimento apropriada a cada realidade social, considerando a diversidade cultural (HOFSTATTER; OLIVEIRA; SOUTO, 2016).

Embora com um percentual elevado de afirmações positivas sobre a contextualização da EA, somente $20 \%$ dos docentes afirmaram usar literaturas específicas para tal (Gráfico 1). É um percentual muito baixo, visto que os próprios livros didáticos trazem nos seus encartes relações de fontes sobre os conteúdos que podem ser trabalhados, indicação de filmes, documentários, dentre outros meios para ampliar as aulas sobre EA. Em sentido contrário ao que se colheu, defende-se a ideia de que a teoria é relevante e necessária para fundamentar e melhor compreender a prática (TRISTÃO, 2004).

A minoria dos docentes que utiliza referencial teórico para o trabalho com a EA assim o faz através de teses e artigos científicos, informações adquiridas pelos meios de comunicação e leitura de textos sobre o assunto. Chama à atenção o fato de nenhum professor reportar-se à lei ou programa governamental de EA do Brasil ou da Bahia.

O estado da Bahia adotou como importantes referenciais teóricos para o trabalho de EA nas escolas o "Programa de Educação Ambiental do Sistema Educacional da Bahia-ProEASE- com o objetivo de fortalecer e orientar a EA nos sistemas de ensino (BAHIA, SEC,2015), e a PEEA/BA, sendo uma recomendação do Currículo Bahia aprovado e homologado em 2019 (SEC /BA,2018). 


\section{Do (des)conhecimento da Lei e a necessidade de formação continuada}

Quando os docentes foram inquiridos sobre a participação em curso de formação continuada na área de Educação Ambiental, oferecido pela Secretaria Estadual de Educação do Estado da Bahia, nos últimos 7 anos, dado o início da vigência da Lei em 2011, todos responderam negativamente, contrariando uma das prioridades da Lei, tal qual a formação continuada e permanente de pessoas na seara ambiental, inclusive a disseminação da Lei na educação formal através de formação continuada e jornada pedagógica (BAHIA, 2011; 2019). De igual modo, todos os docentes participantes da pesquisa desconhecem a Lei que trata da Política de Educação Ambiental da Bahia-PEEA/BA.

Situação semelhante foi constatada nas pesquisas realizadas por Melo (2012) e Barbosa e Santos (2015) ao afirmarem que o ambiente escolar é um espaço de possibilidades para o trabalho com a EA amparado na lei, no entanto, esta ainda não se consolidou nos espaços formais de educação, principalmente em escolas do campo do Nordeste brasileiro.

A efetividade das leis ambientais ainda é inexpressiva, seja pela falta de conhecimento na área e/ou a falta de instrumentos para a formação acadêmica dos profissionais da educação, havendo uma correlação entre 0 desconhecimento das legislações ambientais e a sua inefetividade (GUERRA et al., 2019; CÂMARA,2019).

De acordo com o livro "Avaliação e monitoramento de políticas públicas de Educação Ambiental no Brasil" (ANPPEA,2019), no que diz respeito às políticas públicas da $E A$ do estado da Bahia, foi constatado que muitos municípios baianos ainda não institucionalizaram a PEEA/BA (CHAVES et al.,2019), havendo a necessidade de conhecimento sobre a natureza e do desenvolvimento da PEEA/BA (CERQUEIRA et al., 2019, p.363).

A PEE/BA fomenta uma Educação Ambiental formal voltada às questões socioambientais através da potencialização de uma pedagogia participativa permanente, integrada e multidimensional, ante ao fato de haver uma lacuna na formação inicial dos professores e professoras (CERQUEIRA et al., 2019). A formação docente constitui-se "[...] num continuum de ações, informações e conhecimentos, ao longo da trajetória profissional que é coletiva" (TRISTÃO; 2004, p. 220).

Todos os docentes pesquisados afirmaram ser relevante o oferecimento de cursos de formação continuada pelo Estado da Bahia sobre a temática da Educação Ambiental. Opinião corroborada por trabalhos da comunidade acadêmica envolvendo a temática da formação de professores em EA como fundamental para a qualidade da educação, sendo uma demanda urgente (ATTAINI; SORRENTINO, 2018; DE AZEVEDO MARTINS, SCHNETZLER, 2018; CERQUEIRA et al., 2019; CÂMARA, 2019).

Para a efetividade do trabalho do professor com relação a temática ambiental, $70 \%$ dos docentes in loco sugeriram a formação continuada, 
apontada como a ação mais importante seguida de participação em fóruns, cursos e congressos (10\%), e outros $20 \%$ não responderam(Tabela 2).A Educação Ambiental não pode ser disseminada e discutida apenas em encontros ou momentos pontuais, necessita ser discutida no cotidiano, com todos os seres humanos (CARRAMILLO-GOING; CORTELLA, 2017).

Tabela 2: Sugestões para efetividade da EA, pelos docentes de uma escola pública de CuraçáBahia.

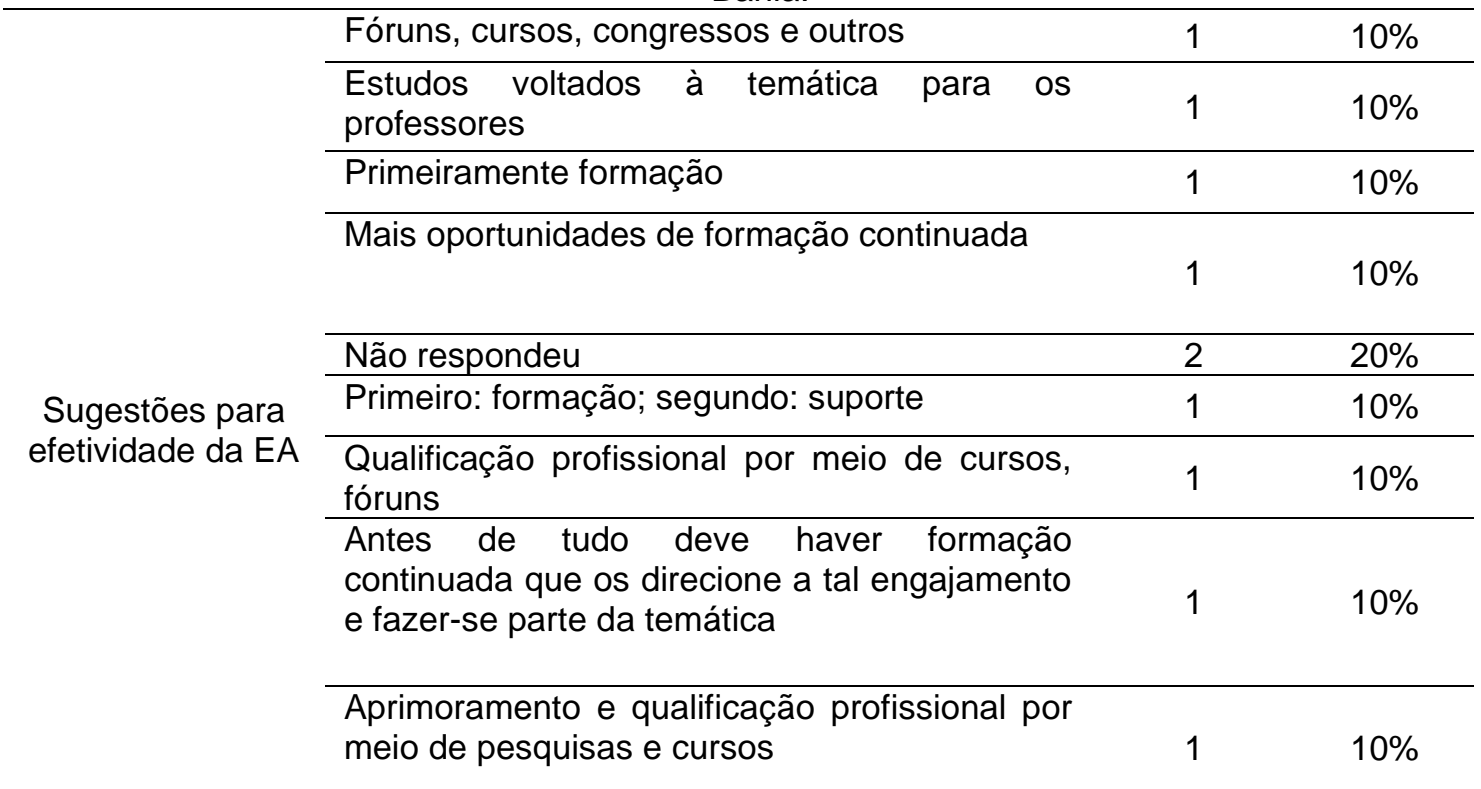

Fonte: Elaborada pelos autores, a partir de dados da pesquisa.

O Decreto Regulamentar 19.083/2019, publicado oito anos após o início da vigência da Lei, ultrapassando, e muito, o prazo de 180 dias que a Lei previu para a sua regulamentação (BAHIA, 2011, art.40), determinou, tardiamente, como se dará o processo de formação continuada dos professores para o conhecimento da PEEA/BA (BAHIA,2019). Com isso, "as legislações, fruto de negociações sociais e políticas, abrem espaço para as iniciativas de educação continuada, ao mesmo tempo em que também as delimitam" (GATTI, 2008, p. 7).

Importa mencionar que a Carta Magna de 1988(BRASIL,1988), a Lei de Diretrizes e Bases da Educação Nacional-LDBEN(BRASIL,1994) e o Plano Nacional de Educação-PNE(BRASIL,2014) salvaguardam 0 direito dos docentes à formação continuada. $E$ isso independe da área a qual se reportam, inclusive o direito à formação mais complexa, como mestrado e doutorado (NASCIMENTO; DE SOUZA NOGUEIRA; RAMOS,2019).

De acordo com pesquisa realizada sobre dilemas e desafios da Educação Ambiental no cenário acadêmico, constatou-se que os docentes, seja em qualquer nível, consideram-se inabilitados para serem educadores ambientais, por motivos variados, porém, cumpre defender a ideia de que todo 
docente deve e pode ser um educador ambiental, independentemente da área de atuação (PROFICE,2016)

A mesma autora defende a ideia de que, da mesma forma com que os docentes investiram na competência digital, podem desenvolver habilidades auto didáticas para a compreensão e ação sobre a EA. Os problemas ambientais são urgentes e demandam um posicionamento por parte das instituições, governos, corporações e, sobretudo, das pessoas; os sistemas de ensino fragilizados perdem seu papel formativo para a mídia, que muitas vezes representa interesses políticos e econômicos (PROFICE,2016).

Para a superação da fragilidade da Educação Ambiental, uma dica seria colocá-la no centro do currículo e não mais por meio dos projetos pontuais práticos, e uma formação permanente e empenhada com a qualidade de vida para escolas sustentáveis (DA SILVA MAIA,2019).

A EA pode ser considerada um instrumento de potencialização de pensamentos e ações, de resistência ao instituído e aos universalismos, contestar as verdades educacionais e o modelo hegemônico da sociedade vigente, além de uma infinidade de coisas (HENNING,2019). Pode ser, também, o uso do conhecimento científico para a busca de "soluções sociotécnicas sustentáveis" (PIRES,2011).

\section{Considerações finais}

$O$ presente estudo trouxe à lume a fragilidade com que a EA desenvolve-se no contexto da educação formal brasileira, apesar de constatado alguns avanços quanto a elaboração de normas e de programas governamentais. A ausência de oferta da EA nos cursos de graduação, a falta de políticas públicas eficazes para a formação contínua e permanente dos professores são apontadas como óbice ao trabalho efetivo da EA na educação básica.

A Política Estadual de Educação Ambiental do Estado da Bahia (Lei 12.056/2011), respaldada em normas anteriores a sua criação, ainda não foi consolidada nos saberes e práticas dos docentes pesquisados, realidade essa que se assemelha a outras localidades no Semiárido brasileiro e em território nacional, quando se trata da efetividade da legislação em matéria de EA.

Um aspecto positivo por parte dos docentes pesquisados está em reconhecerem as fragilidades ou ausência da EA nas suas práticas pedagógicas, o que requer medidas iniciais urgentes por parte do poder público, para que as premissas da lei possam ser exequíveis. E não basta conhecer a Lei, é necessário a formação contínua e permanente em uma EA crítica, contextualizada e emancipatória, para proporcionar uma melhor adequação da lei à qualidade de vida das pessoas em seus Territórios de Identidade, com respeito a todas as formas de vida e uso racional dos recursos naturais. 
Salienta-se que a escola pesquisada apresenta desafios característicos das escolas do campo como um todo, a exemplo de situar-se geograficamente distante da sede do seu órgão administrativo hierarquicamente superior e ser um locus mais acentuado da inefetividade da EA. Uma saída seria incluir a EA no centro do currículo e criar oportunidade para os profissionais da educação participarem de formação continuada e permanente, com reflexões críticas, contextualizadas e emancipatórias.

Enquanto isso não acontece, seria interessante os docentes utilizaremse de suas habilidades autodidatas para a apropriação da vasta literatura e legislação já produzidas nessa área, dado que as políticas públicas de valorização docente podem não ocorrer ou ocorrerem a longo prazo. De modo mais prático, seria cabível a implantação da Agenda 21 nas escolas da educação básica, através das Comissões de Meio Ambiente e Qualidade de Vida (COM-VIDA), proposta recomendada em documentos e programas governamentais para o trabalho de EA nas escolas de todo o país.

Ressalte-se que a presente pesquisa buscou verificar e compreender as aplicações da EA em um determinado locus, muito mais do que apontar críticas à unidade escolar. Através desse diagnóstico da realidade de parte de um Território de Identidade da Bahia, reflexões e ações podem surgir como possibilidade da operacionalização da PEEA/BA em busca da tão almejada sustentabilidade das várias dimensões que a constituem.

Não se pode cair na ingenuidade de achar que a EA, sozinha, resolverá todos os problemas ambientais. No entanto, ela constitui-se em um instrumento potencializador das transformações do modo de vida das pessoas e das relações que estabelecem com o seu meio ambiente no sentido mais complexo.

\section{Referências}

ARAÚJO, S.M.S. A região semiárida do nordeste do Brasil: questões ambientais e possibilidades de uso sustentável dos recursos. Revista Rios Eletrônica, n. 5, p. 89-98, dez. 2011.

ATTAINI, V.; SORRENTINO, M. Educação Ambiental e escola: narrativas de moradores de Fernando de Noronha - PE. REMEA - Revista Eletrônica do Mestrado em Educação Ambiental, v. 35, n. 2, p. 292-314, ago. 2018.

BAHIA. Decreto 19.083 de 07 de junho de 2019. Regulamenta a Lei $n^{-}$ 12.056, de 07 de janeiro de 2011, que institui a Política de Educação Ambiental do Estado da Bahia, e dá outras providências. Salvador:2019.

BAHIA. Decreto no $\mathbf{1 2 . 3 5 4}$ de 25 de agosto de 2010. Institui o Programa Territórios de Identidade e dá outras providências. Disponível em: https://governoba.jusbrasil.com.br/legislacao/1024959/decreto-12354-10. Acesso em: 06 nov.2019.

BAHIA. Documento Curricular Referencial da Bahia para Educação Infantil e Ensino Fundamental. Salvador: SEC, UNDIME,2018. 
BAHIA. Programa de Educação Ambiental do Sistema Educacional da Bahia- ProEASE/ Secretaria de Educação do Estado da Bahia.2 ${ }^{\mathrm{a}}$ EdiçãoSalvador:SEC,2015.

BAHIA. Secretaria de Planejamento- SEPLAN. Disponível em: http://www.seplan.ba.gov.br/modules/conteudo/conteudo.php?conteudo=17.

Acesso em 04 nov.2019.

BAHIA. Superintendência de Estudos Econômicos e Sociais da Bahia-SEI. Disponível em:

$<$ https://www.sei.ba.gov.br/images/informacoes por/territorio/indicadores/pdf/se rtaodosaofrancisco.pdf>. Acesso em 04 nov. 2019.

BARBOSA, G.K.A.; DOS SANTOS, E.M. Educação Ambiental no semiárido: uma revisão sistemática das experiências e práticas. Ambiente \& EducaçãoRevista de Educação Ambiental, v. 20, n. 1, p. 66-86, 2015.

BARDIN, Laurence. Análise de conteúdo. Lisboa: Ed. 70. 2002.

BRASIL. Constituição da República Federativa do Brasil de 1988. Brasília:DOU,1988.

BRASIL. Instituto Brasileiro de Geografia e Estatística(IBGE). Disponível em: https://cidades.ibge.gov.br/. Acesso em: 23 dez.,2019.

BRASIL. Lei no 13.005, de 25 de junho de 2014. Aprova o Plano Nacional de Educação - PNE e dá outras providências. Brasília: DOU,2014.

BRASIL. Lei $n^{\circ}$ 9.795, de 27 de abril de 1999.Dispõe sobre a Educação Ambiental, institui a Política Nacional de Educação Ambiental e dá outras providências. Brasília:DOU, 1999.BRASIL.

BRASIL. Ministério do Desenvolvimento Regional. Superintendência do Desenvolvimento Regional-SUDENE. Delimitação do Semiárido. Brasília-DF, 2017. Disponível em: http://sudene.gov.br/delimitacao-do-semiarido.Acesso em 26 set.2019.

BRASIL. Resolução no 2, de 15 de junho de 2012. Estabelece as Diretrizes Curriculares Nacionais para a Educação Ambiental. Brasília: CNE, 2012.

BRASIL. Lei no 9.394, de 20 de dezembro de 1996. Estabelece as diretrizes e bases da educação nacional. Brasília:DOU,1996.

CÂMARA, A.S. Pela introdução de uma Educação Ambiental ecocêntrica: vantagens e desafios. Revista Direitos Humanos e Democracia, v. 7, n. 13, p. 208-222, 2019.

CARNEIRO, B.S.; OLIVEIRA, M.A.S.; MOREIRA, R.F. Educação Ambiental na escola pública. Revista Brasileira de Educação Ambiental (RevBEA), v. 11, n. 1, p. 25-36, 2016.

CARRAMILLO-GOING, L.C.; CORTELLA, M.S. Educação Ambiental e o compromisso profissional com a sociedade na visão de Paulo Freire.eMosaicos, v. 6, n. 13, p. 112-125, 2017. 
CARVALHO, I.C.M. Educação Ambiental: a formação do sujeito ecológico. Cortez Editora, 2008.

CARVALHO, L.D. Os saberes tecidos no contexto: a vertente educativa da convivência com o semiárido fundamentando novas práticas e metodologias pautadas na ontextualização. Salvador. Anais do III Seminário de Educação do Campo e Contemporaneidade, 2012.

CERQUEIRA, A. dos S. et al. Política Pública de Educação Ambiental do Estado da Bahia à Luz das Dimensões e Indicadores da ANPPEA. In RAYMUNDO et al. (Org.). Avaliação e monitoramento de políticas públicas de Educação Ambiental no Brasil: transição para sociedades sustentáveis [recurso eletrônico]. Piracicaba: MH-Ambiente Natural, 2019.

CHAVES, J.M. et al. Socializando o Sistema MonitoraEA em Ofcina de Educação Ambiental em São Francisco do Conde - Bahia. In: RAYMUNDO et al. (Org.). Avaliação e monitoramento de políticas públicas de Educação Ambiental no Brasil: transição para sociedades sustentáveis [recurso eletrônico]. Piracicaba: MH-Ambiente Natural, 2019.

DA SILVA MAIA, Jorge Sobral. Formação permanente de professores e a Educação Ambiental crítica no contexto da escola pública. PRACS: Revista Eletrônica de Humanidades do Curso de Ciências Sociais da UNIFAP, v. 11, n. 2, p. 07-19, 2019.

DE AZEVEDO MARTINS, J.P.; SCHNETZLER, R.P. Formação de professores em Educação Ambiental crítica centrada na investigação-ação e na parceria colaborativa. Ciencia \& Educação, v. 24, n. 3, p. 581-598, 2018.

DUARTE, V.M.N. Pesquisas: exploratória, descritiva e explicativa. Brasil Escola. Disponível em: <https://monografias.brasilescola.uol.com.br/regras-abnt/pesquisasexploratoria-descritiva-explicativa.htm\#>. Acesso em 20 nov.2019.

DUTRA, F.; TERRAZZAN, E. A. E. Reflexos das normativas legais sobre formação de professores da educação básica em configurações curriculares de cursos de licenciatura em química e formação da identidade profissional docente. Ensaio Pesquisa em Educação em Ciências. V.14, n.1, 2012, p. 169-180.

FERREIRA, G. Redação científica: como entender e escrever com facilidade. São Paulo:Atlas,2011.

FERREIRA, J.D.C. Alto Ipojuca: Participação dos usuários (sociedade civil) nas discussões de políticas públicas socioambientais no semiárido Pernambucano. In: SILVA, E.H.; SANTOS, C.A.B.; OLIVEIRA, E.G.S. (orgs.). Histórico ambiental: recursos naturais e povos tradicionais no Semiárido nordestino. 1 ed.-Curitiba: Appris,2017.

FREIRE, P. Educação como prática da liberdade. 31. ed. São Paulo: Paz e Terra, 2008. 
GATTI. B.A. Análise das políticas públicas para formação continuada no Brasil, na última década. Revista Brasileira de Educação, Rio de Janeiro, vol. 13, n. 37, jan./abr.2008.

GUERRA, A.F.S. et al. Reflexões sobre Ações na Política Pública de Educação Ambiental em Santa Catarina In: RAYMUNDO et al. (Org.). Avaliação e monitoramento de políticas públicas de Educação Ambiental no Brasil: transição para sociedades sustentáveis [recurso eletrônico]. Piracicaba: $\mathrm{MH}$ Ambiente Natural, 2019.

HENNING, P.C. Resistir ao presente: tencionando heranças modernas para pensar a Educação Ambiental. Ciência \& Educação (Bauru), v. 25, n. 3, p. 763-781, 2019.

HOFSTATTER, L.J.V.; FERRARO JUNIOR, L.A. Política Estadual de Educação Ambiental na Bahia: desafios à participação democrática. Rev. Eletrônica Mestr. Educ. Ambient. ISSN 1517-1256, V. 30, n. 1, p. 217 - 236, jan./ jun. 2013.

LOUREIRO, C.F.B. Complexidade e dialética: contribuições à práxis política e emancipatória em Educação Ambiental. Educ. Soc., Campinas, vol. 26, n. 93, p. 1473-1494, Set./Dez. 2005.

MELO, M.C.A. Educação e Convivência no Sertão do Pajeú. In: CHAVES, A.M.; CAMPOS, A.L.T. (Org.). Boas práticas em Educação Ambiental na agricultura familiar: exemplos de ações educativas e práticas sustentáveis no campo brasileiro. Brasília: Departamento de Educação Ambiental, MMA, 2012. p. 83-90.

NASCIMENTO, R.C.; DE SOUZA NOGUEIRA, E.M.; RAMOS, P.R. Uma análise da política de Educação Ambiental da Bahia. Revista Ibero-Americana de Ciências Ambientais, v. 10, n. 5, p. 331-344, 2019.

PIRES, I.M.; CRAVEIRO, J.L. Ética e prática da Ecologia humana: questões introdutórias sobre a Ecologia humana e a emergência dos riscos ambientais. Lisboa: APENAS, 2011.

PROFICE, C.C. Educação Ambiental: dilemas e desafios no cenário acadêmico brasileiro. REDE-Revista Eletrônica do PRODEMA, v. 10, n. 1, 2016.

RAYMUNDO, M.H.A.; BIASOLI, S.; BRANCO, E.A.; SORRENTINO, M. (Org.). Avaliação e monitoramento de políticas públicas de Educação Ambiental no Brasil: transição para sociedades sustentáveis (recurso eletrônico). Piracicaba: MH-Ambiente Natural, 2019.

RAYMUNDO, M.H.A.; BRANCO, E.A.; BIASOLI, S. Indicadores de políticas públicas de Educação Ambiental: construção à luz do Tratado de Educação Ambiental para Sociedades Sustentáveis e Responsabilidade Global e da Política Nacional de Educação Ambiental. Cadernos de Pesquisa: Pensamento Educacional, n. esp, p. 337-358, 2018.

REIGOTA, M. O que é Educação Ambiental. Brasiliense, 2017. (E-book). 
RODRIGUES, C.S.; SANTOS, C.C.; PEREIRA, N.R. Educação Ambiental como política pública no Estado da Bahia: um olhar sobre a PEEA-BA. Rev. Eletrônica Mestr. Educ. Ambient. E-ISSN 1517-1256, v. 33, n.2, p. 286-301, maio/ago., 2016.

SORRENTINO, M. Educador Ambiental Popular. In: FERRARO JUNIOR, L. A. (Org.). Encontros e Caminhos: Formação de Educadoras(es) Ambientais e Coletivos Educadores. Vol. 3. Brasília: MMA/DEA, 2013. p.143-153.

TRISTÃO, M. Educação Ambiental e a descolonização do pensamento. REMEA-Revista Eletrônica do Mestrado em Educação Ambiental, p. 28-49, 2016.

TRISTÃO, M. Os contextos da Educação Ambiental no cotidiano: racionalidades da/na escola. 2004. Anais da 27ạ Reunião Científica da Associação Nacional de Pós Graduação e Pesquisa em Educação. Disponível em: <http://27reuniao.anped.org.br/gt22/t229.pdf>. Acesso em: 23 nov. 2019. 